Maurice A. Deane School of Law at Hofstra University Scholarly Commons at Hofstra Law

Hofstra Law Faculty Scholarship

$4-2014$

\title{
Advancing the Shared Parenting Debate, One Step at a Time: Responses to the Commentaries
}

Marsha Kline Pruett

J. Herbie DiFonzo

Maurice A. Deane School of Law at Hofstra University

Follow this and additional works at: https://scholarlycommons.law.hofstra.edu/faculty_scholarship

\section{Recommended Citation}

Marsha Kline Pruett and J. Herbie DiFonzo, Advancing the Shared Parenting Debate, One Step at a Time: Responses to the Commentaries, 52 Fam. Ct. Rev. 207 (2014)

Available at: https://scholarlycommons.law.hofstra.edu/faculty_scholarship/457

This Article is brought to you for free and open access by Scholarly Commons at Hofstra Law. It has been accepted for inclusion in Hofstra Law Faculty Scholarship by an authorized administrator of Scholarly Commons at Hofstra Law. For more information, please contact lawcls@hofstra.edu. 


\title{
ADVANCING THE SHARED PARENTING DEBATE, ONE STEP AT A TIME: RESPONSES TO THE COMMENTARIES
}

\author{
Marsha Kline Pruett and J. Herbie DiFonzo
}

It is gratifying to see that the spirited debate that ensued at the Think Tank remains enlivened in the commentaries. These additional perspectives were supplied by several experts and committed professionals akin to those who participated in the Think Tank. ${ }^{1}$ We wish to thank all of the commentators for thoughtful analyses of what did, and did not, happen at the Think Tank. Each commentary provided a frame of reference useful to us, as the Reporters, in reflecting upon what was achieved and what tasks remain.

Thirty-two professionals, representing a wide variety of disciplines and expertise, convened to discuss the issues surrounding shared parenting practices and policy. ${ }^{2}$ We reached consensus points, as noted in the Final Report and discussed in the commentaries. We also left some of the thorniest issues for subsequent discussion and work, much to the disappointment of some commentators. Reading through the commentaries, we felt a bit of déjà vu. The same divisions that made consensus so elusive at the Think Tank are evident in the nature and breadth of perspectives expressed in the commentaries. To wit:

Three of the six commentators (one legal scholar and two mental health scholars) favored statutory presumptions or guidelines regarding shared parental decision making, although they differed as to whether they endorsed a blanket approval or supported a shared decision-making presumption only under particular circumstances. Two legal practitioners writing together espoused no presumption generally, but would consider shared decision making in specific situations. One mental health scholar opposed presumptions but only for some of the family court populace, and the only judge providing commentary strongly advocated judicial discretion and individual decision making. Clearly, diversity in opinion reigned, just as it did at the Think Tank.

Each of the commentators staked out a position by giving certain considerations preference or value over others. For example, legal practitioners Cognetti and Chmil rejected presumptions and directives, focusing instead on each family's unique circumstances and agreeing with the Think Tank "that the most effective decision making about postseparation custody rights is case specific." However, they allowed room for a presumption that both parents should share in the decision making "when appropriate" if "there is a modicum degree of cooperation and communication between the parents." This hedges all bets, as "modicum" must be defined and "when appropriate" determined on a case-by-case basis. Two mental health researchers (Lamb and Braver) eschewed individualized decision making on the basis that it maintains - and even spurs on - continued parental conflict without evidence that it increases the quality of decisions. Lamb advocated for decisions "informed by clear principles that are based on empirical research and are subject to critical evaluation" and Braver concurred, but he also wondered if "it really matter[s] what the law says or what presumption is in force? Of course it does, but only symbolically." Braver contended that the "buzz" or believed norms about how decisions are made in court exert as much or more influence than the law itself. Scott, a legal scholar, argued for the "approximation" standard adopted by the American Law Institute, which includes a presumption of shared decision-making responsibility and allocates custodial

Correspondence: mpruett@smith.edu 
responsibility on the basis of "the proportion of time each parent spent performing caretaking functions for the child prior to the parents' separation ..."

Mental health scholar Jaffe presented a double-pronged strategy. He "would wholeheartedly support a presumption of joint decision making for all parents who don't go to court," but a case-by-case determination "once parents enter the courthouse and search in earnest for a wise judge ..." Jaffe's concerns focus on protecting vulnerable family members who are victims of domestic violence, and he believes a presumption would put an extra burden of proof and pressure to share decision making even when it may put one parent at continued risk of being threatened or coerced. Miller favored individual determinations, fearing that "a presumption of joint decision making may result in harmful consequences for parents and children," and noting that in her experience of over two decades on the bench "presumptions all too often are applied by the courts reflexively."

Notably, it isn't always clear whether the commentators are discussing decision making versus parenting time or both, the same critique given to the Final Report itself. Only one of the commentaries took on the issue of parenting time specifically and directly. Hence, the commentaries reflect the same kinds of varied viewpoints we encountered in the Think Tank. What this indicates to us is that the Final Report indeed accurately encapsulated the Think Tank discussions and captured what is happening throughout the field. Family law in this area is in methodological and substantive flux, and the Final Report mirrors this reality: the early stage of discussion, the variation of opinion, and the tentative exploration of areas for which consensus was attainable so that the more numerous areas for which there was no consensus could then be approached from some common ground.

As Scott noted, it "was impressive that the group reached consensus on as many issues as it did." The Think Tank indeed pronounced its unanimous "preference for parents' active role in planning for their children's future lives in reconstituted families." The commentators all agreed with this point, and all might agree that's a no-brainer. However, the context surrounding and underlying that agreement was an endorsement of parental autonomy that inched the participants toward questions about the court's essential and nonessential roles and the ways in which social science research might appropriately be used to identify when parental self-determination would leave some family members too vulnerable. We believe that, particularly given the tortuous history of child custody determinations, the decisive push toward negotiated parental autonomy and away from litigated judicial decrees is significant.

Let's look a bit deeper into some of the excellent questions and points raised by the commentators that pertain to the issue of parental autonomy and court intervention:

\section{(a) Parenting Plans}

As Scott emphasized, and Cognetti and Chmil and Jaffe also discussed, the Think Tank participants endorsed mediated parenting choices and detailed parenting plans as two tools for maximizing successful efforts to help parents resolve decision making and parenting time arrangements. The Think Tank did not reach the point of debating whether only voluntary mediation, or also mandatory mediation, is supported by research or a majority of practitioners. Think Tank participants did form a consensus about requiring parenting plans for all families. Numerous jurisdictions already do so, and while the mandates vary in specificity, some statutes require parents to engage in a careful assessment of decision making and parenting time allocation to implement the legislative policy of assuring children frequent and meaningful contact with both parents after separation. ${ }^{3}$ As the Think Tank participants are comprised largely of progressively oriented, alternative dispute resolution-focused professionals, and considering that the majority of participants endorsed individualized planning for shared parenting and decisions for disputes over the same, research and policy that further develops parenting plans seems a logical direction for future discussion.

\section{(b) The Approximation Standard}

In the end, the majority of Think Tank members adhered to the principle that individual determination of the best interests of the child (BIC) should guide parenting outcomes. Scott rejected the 
case-by-case component of the BIC standard. While the scholarly literature has often pointed out its flaws, we believe the BIC standard is akin to Winston Churchill's view of democracy: the worst form of resolution, except for all the others.

Scott continues to make her case for the "approximation" standard, which she proposed in 1992 and which the American Law Institute adopted a decade later. As noted above, this standard purports to avoid or reduce litigation over parenting disputes by offering a presumption for the allocation of parenting time based upon the proportion of time each parent has spent on child rearing in the past. But significant contrary arguments have been raised to the rule. ${ }^{4}$ These range from a concern that the approximation standard is merely the gendered primary caretaker rule in another guise (because the time mothers spend on child care and housework is still twice what fathers spend ${ }^{5}$ ), to the argument that, rather than avoiding litigation, the parental battle would now shift to a contest over the definition and division of the caretaking functions in the past. More problematically, the approximation standard freezes parenting in terms of past behavior, accounting for neither the usual evolution of parental roles over time or, worse, the changing developmental needs of children as they grow. In sum, its argument that the parenting organization of the intact family should simply be carried over to the separated family now having to deal with often radically different household, employment, and child care arrangements has found few takers. To date, only the state of West Virginia adopted the standard and that state did so in an effort to soften its earlier primary caretaker presumption.

\section{(c) Domestic Violence}

Jaffe's critical focus on intimate partner violence [IPV] and its role in parenting determinations is shared by the Think Tank members, as reflected in the Final Report. In fact, it was perhaps the single most important concern that discouraged endorsement of presumptions of parenting time. Again, to suggest that caution should be exercised when there are allegations of IPV is as obvious as the stakes are enormous. Most Think Tank participants believe that cases involving IPV would clearly benefit from individual determinations, and they would also profit from a body of research that might further clarify best practices when violence allegations are raised during parental disputes related to separation and divorce.

Jaffe agreed that shared parenting is a beneficial outcome for children, but he asserted that parents who "enter the justice system to litigate child custody have passed the point where shared parenting should be presumed or encouraged." Our concern is that the entrance to the courthouse may not be the best benchmark for determining whether shared parenting is an option. We submit that Jaffe's division of divorcing parents into two camps, one filled with reasonable parents and the other with litigious ones for whom shared parenting is not a viable option, is an over-simplification of the parents who fill the family courts. Unless the parents have agreed to settle their child-related issues ahead of time, all parents enter the courthouse as "early" litigants. We hope that Jaffe would agree that experience dictates that we should not abandon the possibility of shared parenting for the majority of parents who begin the process of litigating over parenting, since most do resolve their dispute short of a trial and/or judicial decree, and an increasing percentage of these parents end up agreeing to some form of shared parenting.

The processes of negotiation and mediation are intended to help parents see past their break-up into crafting a parenting plan for the future healthy upbringing of their children. Importantly, when there are allegations of IPV, there must be safeguards and cautions in place as safety is paramount, and we must be vigilant about the possibility of IPV even when allegations have not been raised. However, for many cases that do not involve allegations or instances of IPV, we do not believe simply "enter[ing] the justice system to litigate child custody" ought to disqualify parties from considering a shared parenting arrangement.

(d) The Problem with Individualization

As Lamb points out, the famous Goldstein, Freud, and Solnit proposals of the 1970s were "bold and conclusive," while the Think Tank Final Report reflects "increased awareness of the complexity of the 
issues that need to be considered when making life-altering decisions about children's future relationship with their parents." Those bold assertions from the 1970s turned out to be, as Lamb acknowledges, "simplistic" and, many would add, wrong-headed. Or at least, too narrow for the populations represented in family court, especially since the Goldstein, et al. data were drawn from adoption disputes, not parenting contests between two biological and//or psychological parents. By contrast, as Lamb notes, the Final Report is "broad-ranging and comprehensive," which reflects the scope and intent of the Think Tank members. The absence of audacity and definitive resolution was a clear disappointment to our colleagues Braver, Lamb and Scott. We submit that it was too soon to be bold. A face-to-face discussion and cross-pollination of disciplines and perspectives was the initial task and to that end the Think Tank was fairly successful in identifying the roadblocks and suggesting ways forward. In this controversial arena where public rancor has often bedeviled reason, we believe that the benefits of this Think Tank's analysis will emerge over time and will hold longer-term if we consider this a process rather than an event. One outgrowth from the partnerships begun at the Think Tank may be found in the companion articles to the Final Report printed in this FCR Special Issue.

Some of the commentators, Lamb eloquently among them, highlight problems with individualized decision-making. Lamb expresses a desire for evidence-based practice. While this is a laudable goal, it isn't entirely clear from our Final Report or the commentaries how evidence-based practice will be put to use to assist in the resolution of the issues involved in considering shared parenting presumptions. For example, one of the policy tensions articulated juxtaposes the need for providing children with stability and consistency, and the desire to encourage two-parent involvement. Substantial research bases exist for each of these propositions, but research has not yet been able to test which of these empirically demonstrated developmental and familial conditions should prevail if we are forced to choose between them. It isn't clear yet if the choice can be avoided, and what types of considerations are paramount. Moreover, the balance would likely differ across situations.

We particularly appreciate Lamb's comment that neither the Think Tank nor the Final Report considered whether "practice would be best if empirically based guidelines were administered in individually sensitive ways, perhaps by recognizing and formulating recommendations sensitive to [family] similarities." We personally believe this to be true, and do not feel that empirically based frameworks need to reach the level of presumptions, but they would in fact address some of the problems noted with strictly individualized decisions. Some articles addressing empirically based frameworks appear in the companion articles that stemmed from the Think Tank (e.g., see Part I and II articles in this FCR issue by McIntosh, Pruett, \& Kelly and Pruett, McIntosh \& Kelly on overnights). Given the diversity of views, disciplines, and backgrounds among the 32 professionals, the Final Report endeavored to detail how the groundwork was laid for these next papers to be developed, and how such papers are encouraged, ideally, by practitioners and researchers from differing disciplines and who have perspectives at variance with one another.

Like Lamb, Braver emphasizes the costs of individualized decisions in the absence of guidelines. He quotes Barbara Woodhouse's observation that unpredictability leads parents "to litigate custody disputes rather than settle them." He argues that our legal system does not know how properly to make case-specific resolutions. There is much to be said for this viewpoint, although we would add that the track record on presumptions is entirely unproven. These considerations lead us back to a second major focus of the Think Tank: use of empirical research in legal decision-making. Along with the commentators, the members of the Think Tank are engaged in a major effort to change the legal culture for divorcing families. The Think Tank endorsed social science research as a way to bring these principles to the art of decision-making. It also focused on ways in which the science, when applied too broadly (e.g., applied to populations which have not been studied) or taken out of the public policy realm and brought into individual case decisions, might create pitfalls rather than benefits. The Final Report focused on what these pitfalls are and how they might be recognized. The next steps are to elucidate what the evidence bases are and how they can be judiciously applied to support parents and other decision makers when confronted with conundrums and situations in which reason has given way to conflict and truth is obscured. Then, as Lamb points out, empirically driven information about certain kinds of issues and problems can be brought to bear on individual considerations. 


\section{(e) 20-20 Hindsight}

There are always options recognized as better ones in hindsight. Cognetti and Chmil suggested that the Think Tank would have benefited from the input of more actively practicing attorneys. We agree. We are hopeful that their statement that the way in which the Final Report groups the many shared parenting considerations (also known as factors) "should clearly become a model for statutes" offers a pathway to move the field forward.

The Think Tank members were not asked to vote on definitive proposals. A few "straw polls" were taken to get a sense of where the group stood to guide discussion, and the tallies were accordingly not recorded. Suffice it to say that the opinions appeared to be divided along lines familiar to all of us working in this field: concerns for equity in parenting time decisions made by third parties other than the parents themselves drove the support for a parenting time presumption. The majority view of support for shared decision-making was discussed as an outgrowth, at least partially, of the reality that many states are already awarding shared decision-making in most instances, as Braver points out in his commentary. But the voices in opposition did so on the basis of strain and impracticality in cases of distance or conflict.

A final 20-20: This Think Tank was called to examine two significant issues which in retrospect proved to be rather distinct: one was shared parenting law and policy; the other was how properly to develop and rely on the social science research on or pertaining to shared parenting. The Final Report reflects our attempt to weave these two strands into a coherent whole and provide some basis for moving forward. While the ultimate goal remains to produce a coherent whole in which research provides a rich backdrop for assessing shared parenting law and policy, we were only partially successful in this integration. We look forward to creating the tapestry together, two steps forward, one step back, as progress so often gets made. ${ }^{6}$

\section{(f) Concluding Remarks}

From all this, we take some of the commentators' questions, suggestions, and directions as compass points for next steps.

1. Delineate through debate and research how presumptions and guidelines can minimize familycourt related conflict and increase the sense of fairness in the law; and explicate under what conditions they will be harmful to these goals (see articles by Ver Steegh \& Gould-Saltman and also Brinig, Frederick, \& Drozd in this issue).

2. Prioritize the research agenda and find ways of exploring together questions raised by the Think Tank and commentators.

3. Define individualization and analyze in detail its strengths and weaknesses.

4. Compare and evaluate guidelines that have been suggested by countries, states, or provinces on the basis of empirical evidence relevant to various aspects of shared parenting (e.g., young children and overnights; when domestic violence is present or alleged; and so forth). Articles in this FCR issue establish some forays into these areas, with more discussion undoubtedly to follow from these insights.

5. Identify how the law can best facilitate productive shared parenting and revisit the issue of court enforcement of parental agreements to better delineate under what conditions this would or would not be supported in the field.

6. Recognize and separate out the political advocacy goals from the social science evidence, clinical as well as judicial experience, and parental input that guide effective decision-making.

Ultimately, the most salient contribution of the Final Report may be its focus on finding ways to better support those who are making case-specifics: the parents themselves. The Final Report strongly advocates universal adoption of parenting plans as integral to all custody resolutions, along with expansion of mediation and other alternative dispute-settling methods. Along with the commentators, 
the members of the Think Tank are engaged in a major effort to change the legal culture for divorcing families. Many disagreements remain about specific proposals, and much further research awaits completion. But we believe that the Think Tank and all of the commentary it has inspired to date and forthcoming, will inevitably serve the task of supporting parents in raising their children and continuing to nurture them into adulthood.

\section{NOTES}

1. Note that the commentators were not selected by the Co-Reporters, but by the Editor of the Family Court Review, Andrew Schepard, in consultation with the Think Tank Co-Chairs, Arnold Shienvold and Peter Salem, with the intent of producing a diversity of views in order to further expand the discussion. An additional commentary from a judge was expected but not completed due to personal exigencies.

2. A brief terminology reminder from the Final Report: legal custody is referred to as decision-making and physical custody as parenting time.

3. See, e.g., Ariz. Rev. Stat. § 25-403.02 (2013), Fla. Stat. § 61.13(2) (2013), and N.M. Stat. § 40-4-9.1 (2013).

4. See, e.g., Richard A. Warshak, Parenting by the Clock: The Best-Interest-of-the-Child Standard, Judicial Discretion, and the American Law Institute's "Approximation Rule," 41 U. BALT. L. REV. 83 (2011).

5. See Pew Research Center, Parents' Time with Kids More Rewarding Than Paid Work-and More ExhaustING, Oct. 8, 2013, at 6, available at http://www.pewsocialtrends.org/files/2013/10/parental-time-use_10-2013.pdf.

6. Cognetti and Chmil object to the Final Report's statement that both the paternal preference rule and the tender years' presumption reflected the common law's view that only one parent could serve as the primary caretaker after divorce. But that is precisely what those doctrines show, as joint custody was anathema to the common law and not available in most states until the 1980s. The abolition of the maternal preference standard, hand-in-hand with the rise of no-fault divorce, left courts without a presumptive rule favoring one parent. This argument is developed more fully in J. Herbie DiFonzo, From the Rule of One to Shared Parenting: Custody Presumptions in Law and Policy (this issue). 